\section{Environmental influences on aggression: The facilitation of modeling effects by high ambient temperatures*}

\author{
ROBERT A. BARON $\dagger$, Purdue University, Lafayette, Ind. 47907 \\ and \\ SANDRA F. LAWTON, University of South Carolina, Columbia, S.C. 29208
}

Forty undergraduate males participated in an experiment designed to investigate the hypothesis that the influence of an aggressive model on the subsequent behavior of adult Os would be enhanced by uncomfortably high ambient temperatures. In order to examine this suggestion, a 2 by 2 factorial design based upon two levels of ambient temperature (cool, hot) and two levels of exposure to the model (no model, model) was employed. Results indicated that, consistent with the findings of previous research, aggression was facilitated by exposure to the model. In addition, support was obtained for the prediction that the influence of the model would be enhanced by high ambient temperatures.

It has frequently been contended that ambient temperature exerts an important influence upon human aggression. More specifically, the view that uncomfortably high temperatures contribute to the outbreak of both individual and collective violence has won widespread general acceptance (e.g., U.S. Riot Commission, 1968). Two types of evidence are generally marshaled in support of this suggestion.

First, both informal observation and laboratory findings indicate that we are often more irritable and prone to outbursts of "temper" under uncomfortably hot than under comfortably cool conditions (e.g., Griffitt \& Veitch, 1971). Second, it is indeed the case that a large proportion of the serious intances of civil disorder which have taken place in the nation's cities in recent years have occurred during the hot summer months (Goranson \& King, 1970; U.S. Riot Commission, 1968). Considered together, these observations and findings provide consistent evidence for the existence of a close and important relationship between ambient temperature and human violence.

However, the presence of a direct and straightforward link between ambient temperature and human

*This research was supported by Grant GS-3230 from the National Science Foundation to the senior author. The authors wish to express their sincere appreciation to Kent Eargle, Dennis Mullaney, and Michael Tkacik for their able assistance in the collection of the data, and to Donn Byrne for his comments on a previous version of the manuscript.

tRequests for reprints should be sent to Robert A. Baron, Department of Psychology, Purdue University, Lafayette, Ind. 47907. aggression has recently been called into question by the results of an experiment conducted by the author (Baron, in press). Specifically, the findings of this study indicated that high temperatures in and of themselves do not always serve to facilitate aggressive actions and may, under certain conditions, actually serve to inhibit such behavior. In view of this new and apparently contradictory evidence, it seemed important to examine the effects of ambient temperature on human aggression more closely. In particular, an attempt to uncover the mechanism through which this factor might influence the incidence or magnitude of aggressive acts appeared to be merited. The present experiment represented a first step in this direction. Specifically, it was designed to examine the hypothesis that high ambient temperatures serve to facilitate or enhance human violence by increasing the susceptibility of Os to influence from an aggressive model (see, e.g., Bandura, Ross, \& Ross, 1963; Wheeler \& Caggiula, 1966).

In order to examine this hypothesis, Ss in two groups were provided with an opportunity to aggress against a peer victim under comfortably cool or uncomfortably hot conditions. Within each of these groups, half of the individuals were exposed to the actions of a highly aggressive model before attacking the victim, while the remaining half aggressed in the absence of such experience. In accordance with the suggestions made above, it was predicted that the model would be more effective in raising the level of aggression shown by Ss under the hot than under the cool condition.

$$
\text { SUBJECTS }
$$

Forty male undergraduates enrolled in sections of elementary psychology at the University of South Carolina participated in the study. Students took part in the experiment in order to fulfill a course requirement.

DESIGN AND APPARATUS

A 2 by 2 factorial design based upon two levels of temperature (cool, hot) and two levels of exposure to an aggressive model (no model, aggressive model) was employed. Ten Ss were assigned randomly to each cell of this design.

The apparatus consisted of a modified Buss "aggression machine" (Buss, 1961), a Lafayette stop clock (Model $20225 \mathrm{~A}$ ), two different lists of $40 \%-60 \%$ Glaze association-value nonsense syllables, and an intercom system. A more detailed description of this equipment is presented in previous articles (Baron, 1971a, b, c).

\section{PROCEDURE}

When Ss arrived for the experiment, they were met by the $\mathrm{E}$ and two confederates (C 1, C 2). The $\mathrm{E}$ then explained that the first part of the study was concerned with attitudes and opinions and requested that all three individuals fill out a 23-item attitude questionnaire dealing with a wide range of issues. This task was employed solely as a time filler to insure that Ss spent sufficient time in the experimental rooms for any influence of ambient temperature on their behavior to be apparent. In order to spare the two confederates repeated exposure to high temperatures, however, both worked on their questionnaires in different rooms than the $\mathrm{S}$, where cool conditions prevailed in all instances.

\section{Anger Arousal}

Following the completion of the above procedures, all Ss were exposed to relatively strong provocation from the future victim (i.e., C 1). The procedures employed for this purpose were highly similar to those used in previous research (Baron, 1971a, b, c) and will not be described in detail here. Briefly, the $S$ and the future model (i.e., C 2) were asked to offer a written solution to a problem posed by the $\mathrm{E}$ (how to control rising crime rates) and were then presented with evaluations of their work by $\mathrm{C} 1$. The evaluations presented by this individual were very unfavorable and insulting and served as the major means for angering Ss in the present study.

\section{Aggression Opportunity}

and Exposure to the Model

After the conclusion of the above procedures, Ss participated in a third and final portion of the experiment. During this phase, $\mathrm{S}$ and the model (C2) played the role of teachers and were instructed to punish the victim (C1), who played the role of learner, 
Table 1

Median Intensity of Shocks Delivered to the Learner by Ss in Four Groups

\begin{tabular}{lcc}
\hline & \multicolumn{2}{c}{ Temperature } \\
\cline { 2 - 3 } Model Condition & Cool & Hot \\
\hline No Nodel & $4.28(2.55-8.05)$ & $3.78(1.60-6.25)$ \\
Model & $5.50(1.00-8.15)$ & $6.93(2.70-8.50)$ \\
\hline
\end{tabular}

Note-Numbers in parentheses represent the range of scores for each group.

with electric shocks whenever he made an error in a paired-associates learning task. These noxious stimuli were delivered to the learner by means of 10 buttons on the Buss aggression machine, which were described by $E$ as controlling different intensities of electric shock. In order to convince Ss that the machine was in fact operational, sample shocks were administered from Buttons $4(36 \mathrm{~V})$ and $5(50 \mathrm{~V})$ of this apparatus. In actual fact, however, the learner received no shocks during the study and followed a prearranged pattern of responses (which included a total of 20 errors) during the session.

Following the administration of the sample shocks, the E selected either $S$ or the model (C2) to serve as the first teacher. In the aggressive model condition, C2 was chosen to play this role, while in the no-model condition, $\mathrm{S}$ was designated as the first teacher. Under both conditions, the model acted in a highly aggressive manner when it was his turn to serve as teacher, punishing errors by the learner with shocks from Buttons 8, 9, or 10 . Since the model responded before the $S$ only in the aggressive model condition, however, it is apparent that he could influence S's behavior only in this group.

\section{Ambient Temperature}

The manipulation of ambient temperature was extremely straightforward. In the cool condition, all phases of the experiment were conducted under comfortably cool temperatures, while in the hot condition, all phases took place under uncomfortably high temperatures. These variations in temperature were produced by means of electric heaters and air conditioners, which were used to raise or lower the temperatures in the experimental rooms to the desired levels. Readings of ambient temperature were taken both before and after each session in both rooms. In the cool condition, the average before and after readings were $74.2^{\circ} \mathrm{F}$ and $75.2^{\circ} \mathrm{F}$ in the first room and $74.3^{\circ} \mathrm{F}$ and $75.2^{\circ} \mathrm{F}$ in the second room. In the hot condition, the corresponding readings were $99.0^{\circ} \mathrm{F}$ and $96.0^{\circ} \mathrm{F}$ in the first room and $99.1^{\circ} \mathrm{F}$ and $95.8^{\circ} \mathrm{F}$ in the second.

\section{RESULTS}

The major dependent measure of aggression was the intensity of the shocks delivered to the learner by Ss on occasions when he appeared to make errors in the experimental task. ${ }^{1}$ Because these data were skewed and showed marked heterogeneity of variance, they were subjected to nonparametric analyses.

Table 1 presents the median levels of shock delivered to the learner by Ss in each of the four experimental groups. A Kruskal-Wallis analysis of variance performed on these data indicated that the groups differed significantly in level of aggression $\left(x^{2}=15.85, \quad\right.$ df $\left.=3, \quad p<.01\right)$. Follow-up comparisons among the groups by means of Mann-Whitney $U$ tests revealed that, as suggested by the pattern of medians shown in Table 1, exposure to the model produced significant increments in the intensity of Ss' attacks against the victim in the hot condition $(\mathrm{U}=13.5, \mathrm{p}<.02)$, but failed to produce a similar effect in the cool condition $(\mathrm{U}=34.5, \mathrm{p}>.10)$ Thus, support was obtained for the prediction that the influence of the model would be enhanced by high ambient temperatures. Additional comparisons between the groups indicated that high ambient temperatures neither facilitated aggression in the model condition $(\mathrm{U}=46.0, \mathrm{p}>.10)$ nor inhibited such behavior in the no-model condition $(\mathrm{U}=37.0, \mathrm{p}>.10)$. It appeared, therefore, that this environmental factor influenced Ss' behavior only indirectly, through the enhancement of modeling effects.

\section{DISCUSSION}

Recent mass-media reports of instances of collective violence have frequently cited the "long hot summer" as a contributing factor in such occurrences. More specifically, it has often been suggested that these events are attributable, at least in part, to the "heat wave" conditions prevailing at the time of their initiation (Goranson \& King, 1970). The findings of the present experiment provide some suggestive evidence concerning the manner in which high ambient temperatures may act to enhance such violent outbursts. In particular, they indicate that uncomfortably hot environmental conditions may facilitate the aggression-eliciting influence of aggressive models and so increase the likelihood of large-scale violence in many tense and potentially dangerous situations. Pursuing the analysis of this phenomenon somewhat further, it may be the case that, as suggested by a theoretical framework recently outlined by Bandura (1971), high ambient temperatures serve to increase Ss' levels of emotional arousal and so enhance their tendency to engage in aggressive acts in the presence of violent models. Further research, perhaps employing physiological measures of emotional arousal, is clearly needed to determine if this is indeed the case.

In one important aspect, the results of the present investigation agree closely with those of a previous experiment (Baron, in press). In this earlier study, high ambient temperatures were found to produce a significant reduction in the level of shocks delivered by $S s$ to the victim $(\mathrm{M}=0.85)$. A reduction in aggression of almost precisely the same magnitude $(\mathrm{M}=0.82)$ was observed in the comparable groups of the present study (i.e., the no-model condition). Although this reduction in aggressive behavior failed to attain significance, the fact that similar experimental treatments produced almost identical effects in two investigations separated in time by more than a year suggests very strongly that ambient temperature may indeed be a reliable and important determinant of human aggression. Further investigations designed to examine the influence of this factor, as well as its possible interactions with various social determinants of aggression, are currently planned.

\section{REFERENCES}

BANDURA, A. Social learning theory of aggression. In J. F. Knutsen (Ed.), Control of aggression: Implications from basic research. Chicago: Aldine-Atherton, 1971.

BANDURA, A., ROSS, D., \& ROSS, S. A Imitation of film-mediated aggressive models. Journal of Abnormal \& Social Psychology, 1963, 66, 3-11.

BARON, R. A. Magnitude of victim's pain cues and level of prior anger arousal as determinants of adult aggressive behavior Journal of Personality \& Social Psychology, 1971a, 17, 236-243.

BARON, R. A. Aggression as a function of magnitude of victim's pain cues, level of prior anger arousal, and aggressor-victim similarity. Journal of Personality \& Social Psychology, 1971b, 18, 48-54.

BARON, R. A. Exposure to an aggressive model and apparent probability of retaliation from the victim as determinants of adult aggressive behavior. Journal of Experimental Social Psychology, 1971c, 7, 343-355.

BARON, R. A. Aggression as a function of ambient temperature and prior anger arousal. Journal of Personality \& Social Psychology, in press.

BUSS, A. H. The psychology of aggression. New York: Wiley, 1961

GORANSON, R. E., \& KING, D. Rioting and daily temperature: Analysis of the U.S. riots in 1967 . Unpublished manuscript, Yook University, 1970. 
GRIFFITT, W. \& VEITCH, R. Hot and crowded: Influences of population density and temperature on interpersonal affective behavior. Journal of Personality \& Social Psychology, 1971, 17, 92-98.

United States Riot Commission. Report of the national advisory commission on civil disorders. New York: Bantam Books, 1968.

WHEELER, L., \& CAGGiULA, A. R. The contagion of aggression. Journal of Experimental Social Psychology, 1966, 2 ,
1-10.

NOTE

1. The actual score for each $S$ was the mean intensity of the 20 shocks he delivered to the learner. 